\title{
Clinical Stage 0 Gastric Cancer AJCC v8
}

National Cancer Institute

\section{Source}

National Cancer Institute. Clinical Stage O Gastric Cancer A/CC v8. NCI Thesaurus. Code C133647.

Stage 0 includes: Tis, N0, M0. T is: Carcinoma in situ: intraepithelial tumor without invasion of the lamina propria, high grade dysplasia. N0: No regional lymph node metastasis. M0: No distant metastasis. (AJCC 8th ed.) 